\title{
Human Ecology and Public Policy: Overcoming the Hegemony of Economics
}

\author{
ARRAN GARE
}

ABSTRACT The thinking of those with the power to formulate and implement public policy is now almost totally dominated by the so-called science of economics. While efforts have been made to supplement or modify economics to make it less brutal or less environmentally blind, here it is suggested that economics is so fundamentally flawed and that it so completely dominates the culture of late modern capitalism (or postmodernity) that a new master human science is required to displace it and provide an alternative co-ordinating framework for research and for defining reality. This could then provide an alternative basis for formulating public policy. It is argued that if human ecology is to fill this role, it must be developed on consistently anti-reductionist foundations, and that such a social science would totally reorient public policy from a domain for power elites to a domain for genuinely democratic societies to define and control their destinies.

\section{Introduction: global environmental destruction}

According to the most advanced studies of global warming and its effects:

Large swaths of the planet will be plunged into misery by climate change in the next 50 years, with many millions ravaged by hunger, water shortages and flooding. ... [P] arts of the Amazon rainforest will turn into desert by 2050, threatening the world with an unstoppable greenhouse effect. ... Land temperatures will go up $6^{\circ} \mathrm{C}$ by the end of the next century. ${ }^{1}$

How can we explain a civilisation able to generate such destruction.

Stephen Bunker in his study of the exploitation of the Amazon Basin offers one analysis, an analysis formulated from the perspective of human ecology. ${ }^{2}$ It is the outcome of a globalised market economy characterised by huge concentrations of power. Analysing the flows of usable energy in the world economy, Bunker pointed out the difference between economies of the core zones of the world economy based on production of goods and those in the semi-peripheries and peripheries based on the extraction of resources to trade for such goods. Extractive economies, as they 'develop', use up their reserves, destroy their resources and are impoverished, while the productive economies of the core

2. Stephen Bunker, Underdeveloping the Amazon (Chicago: University of Chicago Press, 1986). 
zones, as they develop, increase their power to dominate and exploit the extractive economies. The regulatory structures of semi-peripheral regions, such as the Brazilian state bureaucracy, become vehicles through which core zones can intensify exploitation of and extraction from the peripheries.

Bunker's study of the exploitation of Amazonia illustrates how the transferral of most of the usable energy in living and fossilise d plants to a small part or the world is generating ecologically costly over-exploitation of natural resources and socially costly hypercoherence. As he pointed out:

Hypercoherence ultimately leads to ecological and social collapse as increasingly stratified systems undermine their own resource base. ... The exchange relations which bind this system together depend on locally dominant groups to reorganize local modes of production and extraction in response to world demand, but the ultimate collapse will be global, not local. The continued impoverishment of peripheral regions finally damages the entire system. ${ }^{3}$

Global warming, due mainly to the burning of fossil fuels in the core zones and to the destruction of rainforests in the peripheries, can be seen as the most obvious manifestation of this undermining of the entire system.

\section{Responding to global environmental destruction}

After detailing the disastrous effects on Amazonia of its interaction with the global economy, Bunker concluded that the only way to prevent such destruction is to radically revalue nature, labour and community and to create an egalitarian human society that sees itself as part of, rather than the master of nature. What is required immediately are changes in the class structure of peripheral countries and efforts to reduce the economic inter-relationships between peripheries and core zones, to allow the peripheries to develop their economies more autonomously.

This is not the direction governments are taking. In fact, policies being adopted throughout the world are the opposite of those suggested by Bunker. Those promoting the kind of policies called for by Bunker are regarded as unrealistic. Why? All deliberations and decisions about what projects to pursue begin with definitions of the situation. These define what is real, including what has happened in the past, what exists, what are the real possibilitie s and what goals are really worth pursuing. Each society has its politics of truth, as Foucault argued, and at different times different discourses have achieved privileged status in defining reality. These then form the basis for deciding public policy. The dominant discourse in the medieval world was theology, in the modern world, science, and now the discourse that defines reality for most people is economics. In the post-modern world of the late 20th century, economics has taken the place of theology, economists have taken the place of medieval priests and the market has taken the place of God. 
Economics is the articulation of the mechanistic world-view to characterise human society. Through the work of Hobbes and the early economists who elaborated Hobbes' ideas, society was construed as a mechanism in which money, functionally equivalent to blood, distributes nutrients to each component of this mechanism. The body as a whole was seen to be moved by its component egoistic individuals struggling in competition with each other to stay alive and satisfy their appetites. Conceived as something that exists and which could be studied, this economy became a reality and the competitive social relations it fostered were then projected by Darwin onto nature. Nature came to be seen as a struggle of all against all and, so conceived, was then used by the social Darwinists as a metaphor for society. Through the incorporation into society of the mechanistic worldview in this way, we have become enclosed in a world where the natural order appears to reflect the social order and the social order appears to exemplify the natural order. ${ }^{4}$

For economists, and now for most other people, what really exists are producers and consumers and markets, means of production, goods and services, and the activities of producing, selling, buying and consuming. The real possibilities are what can be produced, marketed and consumed. The good is what is 'economic' and the 'bad' what is 'uneconomic', as defined by the market. The good of society as a whole is measured by its GNP per head of population and its rate of growth, and by the balance of trade. In the future, despite some environmental destruction and the termination of some low quality, cheap lives, the conditions of most people's lives will improve with improving technology. Progress in this direction will be achieved through the free operation of the market. Nothing must stand in its way. All trade barriers must be abolished and all individuals, all organisations, all countries must subject themselves to the judgement of the global market. We have to accept the dissolution of all communities that cannot survive in the market and we have to accept degradation of the local and global environments unless it can be shown to be more profitable to do otherwise.

If human ecologists such as Bunker are right, then the economists are unrealistic. Public policy should be formulated on the basis of a proper understanding of humans and their relationship to the rest of nature, and this is not being provided by the economists. What can be done? Could human ecology provide the basis for formulating public policy in place of economics? How would it have to be developed to play this role?

\section{The challenge to economics of human ecology}

My contention is that if human ecology has the potential to successfully challenge economics as the basic discourse for defining reality, it is because it is capable of elaborating a challenge to the most basic assumptions of not only economics, but also the underlying mechanistic worldview-which not only economic thought but social reality itself now embodies. It is thereby able to

4. Arran Gare, Nihilism Inc.: Environmental Destruction and the Metaphysics of Sustainability (Sydney: Eco-Logical Press, 1996). 
uphold not only a different conception of nature, but also of humans, human society and of science. It has the potential to provide a total perspective on the human condition, including the present domination of civilisation by economics, to redefine humanity's relation to nature, the relationships between people and the relationship s between individuals and social institutions. It is for this reason that it can redefine what communities are, put in perspective the diverse problems confronting people and redefine the ultimate goals of humanity.

But this is only a potential. To see how ecology might be developed it is first necessary to look more closely at ecology and human ecology.

Ecology is the study of the 'homes' of organisms, or, more precisely, the systems of homes. Eugenius Warming characterised ecology's object of study as 'the manifold and complex relations existing between the plants and animals that form one community' 5 and, developing Warming's ideas, Frederick Clements characterised ecology as 'the science of the community' ${ }^{6}$ Human ecology is the attempt to articulate ecological theory to encompass humanity while giving a place to the distinctive characteristics of humans. Humans, as cultural beings, are able to devise and accumulate methods of coping with life situations, thereby generating community structures and social dynamics without counterpart elsewhere in the animate world. As Martin Hawley summed up the relationship between ecology and human ecology:

[A] workable relationship with the environment is achieved not by individuals or even species acting independently, but by their acting in concert through an organization of their diverse capabilities, thereby constituting a communal system. What is necessary for lower forms of life is even more compelling for human beings. ... [A]n understanding of the relationship of human beings to environment requires a full knowledge of the human social system. Until that is developed, an appreciation of the character of environmental influence cannot advance beyond a rudimentary level. ${ }^{7}$

\section{The philosophy of nature and ecology}

Such characterisations of ecology have not guaranteed a unified research programme. Strongly individualist and reductionist strands emerged within ecology challenging and for some time prevailing against Warming's and Clements' emphasis on 'community'. Human ecology cannot ignore the divisions within the discipline of ecology itself and with the extra problems of dealing with the uniqueness of humans, the problems within ecology generally are exacerbated.

5. Donald Worster, Nature's Economy: A History of Ecological Ideas (Cambridge: Cambridge University Press, 1977), p. 199.

6. Edward J. Kormondy and Daniel E. Brown, Fundamentals of Human Ecology (Upper Saddle River, NJ: Prentice Hall, 1998), p. 29.

7. Amos H. Hawley, Human Ecology: A Theoretical Essay (Chicago: University of Chicago Press, 1986), p. 3. 
The problematic state of ecology requires a more careful consideration of the historical and philosophical foundation s of the discipline. To see what the issues are we need to look at the early history of ecological thought. The roots of ecology go back at least to the tradition of plant geography inspired by Herder and Goethe and established by Alexander von Humboldt as the development of an anti-mechanistic naturalism that saw nature as a dynamic process of becoming. ${ }^{8}$ The underlying causal unity within the world upheld by these thinkers helped inspire the idea that energy is conserved through all transformations of nature. ${ }^{9}$ Correspondingly, forms of life were conceived of as selforganising; that is, as immanent causes of their own becoming and as interdependent both with each other and their environments. Von Humboldt's work inspired the study of the inter-relationships between organisms among figures as diverse as Lyell, Darwin, Agassiz, Thoreau and Edward Suess, the geologist who in 1875 coined the term 'biosphere'.

Corresponding to such ideas about nature, humans were characterised as creative social beings formed by and forming distinctive cultures conditioned by their geographical conditions and striving to realise their unique potentialities. The notion of culture as a defining characteristic of humans was originally put forward by Herder but was developed much further by Hegel. Originally, Hegel saw culture as consisting of three dialectical patterns, the dialectic of representation which operates through language, the dialectic of recognition which operates through moral notions and the dialectic of labour which operates through the use of tools. ${ }^{10} \mathrm{He}$ argued that it is only through coming to participate in these dialectical patterns that we become human, able to conceive ourselves as subjects with an identity (able to say 'I') among other subjects living in a common world. This notion of culture has underlain all subsequent anti-mechanistic theories of human societies.

Human ecology is a development of this tradition of anti-mechanist thought, striving to conceive humans as culturally constituted, yet still part of and potentially creative participants within a dynamic, creative nature, but the original impulse to achieve this has been blunted and confused by the prevailing reductionist tendency within science. The notion of culture, for instance, while still used, has been reduced to an instrument of control. Now, with the development of non-equilibrium thermodynamics, complexity theory and hierarchy theory, the different anti-mechanistic ideas of the progenitors of the tradition can be upheld and reunited. The incorporation of these ideas into ecology provides the basis for a rigorous formulation of human ecology consistent with its original inspiration.

Ecology has been dominated by two competing strands, the 'process-functionalist approach' that treats organisms and their physical environments as integral

8. Alexander von Humboldt, Cosmos, Vol. 1, trans. E.C. Otté (Baltimore, MD: Johns Hopkins University Press, 1997), p. 55.

9. Thomas Kuhn, 'Energy Conservation as an Example of Simultaneous Discovery', in The Essential Tension. (Chicago: Chicago University Press, 1977), pp. 66-104.

10. G.W.F. Hegel, System of Ethical Life and First Philosophy of Spirit, trans. H.S. Harris and T.M. Knox, (Albany, NY: State University of New York Press, 1979), pp. 205-253. 
bio-geo-chemical energetic systems, and the 'population-community approach' that focuses on organisms and viewed ecosystems as networks of interacting populations. ${ }^{11}$ From the perspective of the new science, both these approaches can be embraced as complementary aspects of an anti-reductionist theory while still doing full justice to the distinctive characteristics of humans.

\section{The energetics of ecosystems}

The most useful starting point for studying ecosystems is the process-functionalist approach, beginning with the energetics of ecosystems. The analysis of energy flows, particularly as these have come to be understood with the development of far from equilibrium thermodynamics, enables us to identify some of the generic features of living processes operating in nature. However, it is also necessary to examine the nature of hiearchical ordering, then the specific forms of such ordering and finally, specific life forms and their interactions. The distinctive characteristics of humans can then be fully acknowledged.

From the process-functionalis t perspective the units of selection in ecosystems are conceived as cycles of energy-and-material flow that have different auto-catalytic properties. Organisms tend to be selected by ecosystems that are not only more efficient in their utilisation of energy but are capable of tapping previously unused energy sources. Species are favoured that enter into complex co-operative webs with other species, allowing the ecosystem as a whole to maximise the flow-through of energy. Through such selection the ecosystem as a whole increases the intensity of energy flows and the rate at which matter cycles through the system, increasing both the total diversity and the total biomass.

Humans have been characterised in these terms. According to Richard Newbold Adams, humans, being capable of symbolic communication, are able to transmit culturally acquired knowledge from generation to generation, including the ability to search for more knowledge. ${ }^{12}$ This enables them to continually increase the useful energy forms they are able to exploit. Associated with the growth of such exploitation, humans have developed more complex integrative levels, from bands to tribes, to chiefdoms, to kingdoms, to empires, to nations and then to blocs of nations. With each new integrative level, societies have become more differentiated and hierarchically organised, generating mutually amplifying co-evolutionary systems within these societies. Co-evolution has generated further specialist structures mostly associated with the regulation of society and the means for this regulation (such as educational and research institutions). So long as these emergent levels and specialist structures enable society to find new sources of usable energy and more effective means of exploiting both the environment and subordinate social structures, these more complex social structures will have the power to maintain and extend themselves. This is the

11. R.V. O'Neill, D.L. DeAngelis, J.B. Waide and T.F.H. Allen, A Hierarchical Concept of Ecosystems (Princeton, NJ: Princeton University Press, 1986).

12. Richard Newbold Adams, The Eighth Day: Social Evolution as the Self-Organization of Energy (Austin, TX: University of Texas Press, 1988). 
theoretical framework on which Bunker based his analysis of the global economic system.

\section{The contribution of hierarchy theory}

However, what energetics by itself leaves out is an account of the stability of forms of life. While energetics focuses on how competition increases the flowthrough of energy, the stability of forms of life is based on co-operation or symbiosis between components, central to which are constraints on competition. The cell, for example, is a symbiotic organisation of component processes that evolved independently of each other. As part of the cell, these do not compete with each other. The same is true of multi-celled organisms. Such organisation is characterised by the emergence of hierarchical levels of ordering which constrain constituents to reproduce these levels. The key to emergence is then the concept of constraint. Counter-intuitively, it is constraints that make creativity possible. As Howard Pattee noted:

The constraints of the genetic code on ordinary chemistry make possible the diversity of living forms. At the next level, the additional constraints of genetic suppressors make possible the integrated development of functional organs and multicellular individuals..$^{13}$

To identify hierarchical levels it is necessary to identify different process rates. Behaviour corresponding to higher levels occurs at slow rates, while lower levels are characterised by relatively fast rates.

Taking into account the different temporal and spatial scales and the operation of constraints at these different scales facilitates a better understanding of both organisms and ecosystems. At whatever scale is adopted, an ecosystem will tend to be homeorhetic; that is, it will tend to return to its trajectory of development after a perturbation. Such perturbations are by definition outside the system, but such perturbations can be incorporated into an ecosystem when at a higher level of organisation some control over the abiotic (non-living) environment is established which is uncontrolled at a lower level. For instance, forests control to some degree temperature, levels of humidity and even rainfall that are beyond the control of individual organisms. Nutrient recycling characteristic of rainforests is also an example of incorporation. In this way abiotic elements, such as soils and climates, become incorporated into ecosystems.

In the resulting stabilised environment, species are selected for their compatibility with other species rather than with the physical environment. Complexity can then increase as new species find new ways of exploiting an environment that is becoming more diverse. The process continues in positive feedback fashion, with the increasing stability and diversity of the environment allowing an increasing diversity of species, but the development of such complexity is characterised by limitation s on competition between organisms and species. It is here that studies based on the population-community approach to

13. Howard Pattee, Hierarchy Theory: The Challenge of Complex Systems (New York: George Braziller, 1973), p. 73f. 
eco-systems complement those of the process-functionalist approach. Empirical studies of ecosystems indicate the existence of food webs containing an internal organisation constraining competition, with species grouped into sub-system s or modules. While not completely separate from each other, such modules form components of a hierarchical structure that in both analytical and simulation studies are shown to enhance ecosystem stability.

Instability in ecosystems is associated with the breakdown of hierarchical organisation. The propensity for this is inherent because ecosystems are characterised by positive feedback as well as negative feedback and the effect of positive feedback is likely to overwhelm existing constraints. In such circumstances, either a new set of constraints will form, or the system can degenerate, losing the ability to incorporate perturbations. In such ecosystems the slow rate processes will disappear. No drastic alterations in the environment are required for this to occur.

\section{Human ecology and human culture}

Hierarchy theory also provides new insight into the nature of human culture. Most human ecologists, like Adams, have tended to construe culture as communicable knowledge of how to control the world, but culture is much more than this-it is the complex of processes through which individuals emerge as autonomous agents with an identity - and a more important component of culture is the constraints which make stable social structures possible. To understand this we need to reconsider Hegel's development of Herder's ideas. As we have seen, Hegel conceived human formation whereby people become self-determining agents as involving three dialectical processes, the dialectic of labour, the dialectic of recognition and the dialectic of representation. While human ecologists have focused on the dialectic of labour and considered other aspects of culture only in relation to this, it is the dialectic of recognition that is more important for integrating communities. It is the capacity and need to see themselves from the perspective of others to establish their identities that makes possible the crystallisation of roles and allows complex forms of social organisation. Since the struggle for recognition can only be fulfilled satisfactorily when recognition is reciprocal, this dialectic generates the quest for justice, that is, to give all people their due. ${ }^{14}$ The dialectic of recognition is also behind the impetus to extend knowledge beyond the effort to control things to understand the world, our place within it and our significance; that is, to develop a coherent worldorientation.

Like other emergent hierarchical levels, culture consists of constraints. It is by virtue of the constraints imposed by grammar that we are able to communicate in complex ways. It is by virtue of the constraints associated with recognising the significance of people that we are able to develop complex organisation s capable of achieving what no other species can. This is how human communities are formed, whether these are families, towns, nations, classes, blocs of nations,

14. Axel Honneth, The Struggle for Recognition: The Moral Grammar of Social Conflicts (Cambridge, MA: MIT Press, 1996). 
civilisations or the whole of humanity. Individuals committed to justice and to achieving the understanding necessary to be just are more constrained than are other people, but this is the essence of self-determination. These are the people who have integrity and it is by virtue of their integrity that they can form more enduring relationships with others.

The reproduction of culture takes place from generation to generation. That is, relative to the day-to-day metabolic processes of a society, the processes of cultural reproduction are slow rate processes, but cultures also develop. Hegel argued that through history the tendency has been to move towards increasingly just political, economics and social forms, that is, institution s that recognise more and more adequately the significance, the rationality and the freedom of people. One of his followers, Friedrich Carové, suggested that we are tending toward the 'association of humanity in a divine, fraternal community'. ${ }^{15}$ The cycle of rise and fall of civilisation s and then the tendency for later civilisation s to advance in justice over earlier civilisations, are slower rate processes.

\section{Ecological destruction and human ecology}

While there is much more to life than this abstract analysis acknowledges, it is now possible to reconsider the present predicament of humanity from the perspective of human ecology and to briefly outline the different policies which would follow from the adoption of human ecology as the basis of formulating public policy.

The core problem of humanity's relationship to its ecosystems is not just that humans have acquired ever-new sources of usable energy and new forms of organisation to grow exponentially until they have begun to destroy their environment. The problem is that throughout history humans have learnt to overcome one ecological constraint after another. The overthrow of one set of ecological constraints enabled rapid population growth and the differentiation and expansion of society, but this was then met by new constraints that again limited population growth. Now the constraints of local ecosystems throughout the world, but particularly in the peripheries where lie most of the world's tropical forests, are being destroyed and we are pushing towards the constraints of the global ecosystem, the biosphere. Global warming portends the destruction of the global conditions favourable to humans and the ecosystems that have sustained them.

However, for this to occur, other constraints have been overcome, those associated with culture. Along with developments in technology and means of production, humanity has also been developing organisations embodying more adequate recognition of the significance of people, which has begun to extend to recognition of the intrinsic significance of non-human forms of life. These developments have been supported by the growth of understanding, associated with the development of the arts, literature, philosophy and the sciences. The development of human ecology is part of this.

15. John Edward Toews, Hegelianism: The Path Toward Dialectical Humanism, 1805-1841 (Cambridge: Cambridge University Press, 1980), p. 139. 
The domination by an increasingly integrated ruling class in the core zones of the world economy, now empowered by the development of transnational corporations and sustained by massive exploitation of the global environment, has not only been able to avoid the constraints of institutions committed to justice, but to subvert these institution s and the cultural processes required to sustain them. We now have a global human society in which its most powerful structures are dissolving most of the constraints on human interaction between societies and with the environment. What has greatly facilitated this subversion of justice and of cultural life has been the triumph of neo-liberalism based on social Darwinist neo-classical economics.

\section{Human ecology and public policy}

This is the state of the world understood from the perspective of a consistently anti-reductionist human ecology. From this perspective we can get some idea of what kind of policies would be prescribed if human ecology were to be developed as the basis for defining reality for formulating public policy. Clearly, we would be concerned to identify the long durational processes constituting ecosystems and to ensure that people do not overwhelm these. The aim should be to develop forms of life that can function as components of sustainable ecosystems, ranging from local ecosystems to the biosphere, but human ecology would also redefine the nature of society. Rather than conceiving society as an economic system moved by the egoism of individuals, a fully developed human ecology would conceive human societies as culturally constituted communities within nature and it would reveal the importance for such communities to sustain the longer durational processes of culture's reproduction and development. Finally, instead of abstracting away from power relations as though all that were important were reducing friction in the functioning of the market, human ecology should reveal the power relations within and between communities and organisations and reveal what power relations are required to facilitate the flourishing of human and non-human communities.

With human societies conceived of as emergent phenomena within nature, as communities and communities of communities integrated by cultures, it would be possible to revive and reformulate in naturalistic terms the Hegelian notion that history consists of the self-formation of humanity through the development of cultures. When Hegelianism is reconceived on naturalistic foundations, the advance of recognition associated with this development should be seen as extending to the appreciation of the different environments, histories, traditions and circumstances of people and their local knowledge of these. Institutionalising this recognition implies the modification of old or the creation of new institution $\mathrm{s}$ to appreciate this uniqueness and to cultivate people's autonomy, enabling the diversity of people throughout the world to control their own destinies and develop their unique potentialities. We need to refurbish the notion of 'citizen' and consider what recognising people as citizens entails both for individuals and for community.

We can then redefine public policy so that its ends are seen as the realisation of the highest potentialities of people as creative, culturally constituted and culture 
creating beings able to sustain and augment the natural, social and cultural condition s of their existence. As such, the agents who formulate public policy should no longer be thought of as bureaucrats and politicians, but as the people democratically organised to control their destinies. And developing human ecology so conceived and replacing economics by it should be appreciated as itself part of human self-creation.

Such policy should be formulated on the basis of a proper appreciation of how power operates in and between societies, what kind of power relations are required for the flourishing of both human and non-human life and what power structures could subvert such ends. The kind of hyper-coherence of the ruling elites of the core zones of the world economy, channelling exponentially increasing amounts of energy and nutrients of the global ecosystem and global economy into its further growth, must now be seen as the major problem facing civilisation and the major problem which must be addressed by public policy. What is called for is essentially what Bunker suggested - a radical revaluation of labour and nature, overcoming class divisions, particularly in the peripheral and semi-peripheral regions of the world economy and reducing the economic interactions between different regions of the world. It is necessary to undermine regional exploitation.

We can see from hierarchy theory that one of the conditions for stable structures is the imposition of constraints on the interaction between various parts of a system. These constraints are required to prevent the positive feed back loops which could overwhelm the higher level, slow rate processes - the institution s embodying a commitment to justice. If a global ethico/political order is to prevail it will be necessary to maintain the autonomy of cultural, educational and legal/ political fields incorporating and sustaining the slow processes of humanity's cultural and political development from the economic processes which they should be constraining. Ultimately, to use Karl Polanyi's terminology, it will be necessary to re-embed the market within the community. A condition for achieving this is an organised decentralisation of economic and political power, insulating from each other as much as possible the economies of different communities in different parts of the world. Within each of these different communities, there should again be as much decentralisation as possible, or to put it another way, communities from blocs of nations to nations to cities and bioregions should strive to be as self-reliant economically and self-determining politically as possible. If humanity suffers from the feedback loops generated by the interaction between the regulative and productive sectors of society, then it is also necessary to constrain these interaction s to eliminate such feedback loops. That is, it is necessary to develop organisations in which the differentiations between organisers and the organised, between intellectual and manual workers, are as much as is practically possible overcome. It is necessary to totally reverse the policy directions of the neo-classical economists and neo-liberal politicians and begin the process of creating genuine democracies. 